\title{
Guidelines for nursing homes delivering end-of-life care to residents with dementia across the island of Ireland
}

\author{
Suzanne Cahill, Daphne Doran and Max Watson
}

Suzanne Cahill is an Associate Professor Research Director at Trinity College Dublin, Dublin, Ireland. Daphne Doran is a Care Consultant at Quality Initiatives Consultancy, Belfast, UK. Max Watson is Consultant at the Northern Ireland Hospice, Belfast, UK.

This study was undertaken as part of the Living with Dementia programme based in the School of Social Work and Social Policy, Trinity College Dublin. The authors would like to thank The Atlantic Philanthropies and CARDI for jointly funding this research study and for their on-going interest and support of the work. Their thanks are also extended to nursing home senior staff members and to other government and non-government organisations for their assistance with sample recruitment. A special word of thanks must go to the participants in this study, those men and women from Ireland and Northern Ireland who agreed to be interviewed and who shared with us their personal experiences and testimonies. Thanks are also extended to the eight health service professionals from Ireland and Northern Ireland who read the draft guideline and provided very valuable feedback. They would also like to acknowledge the helpful contributions made by Caroline Forsyth for all research support received including data collection, and Karen Armstrong and Claire Armstrong for their excellent work in typing up the transcripts.

\begin{abstract}
Purpose - This study aims to contribute to improving quality of life for people with end stage dementia living in residential care settings by investigating the experiences of elderly spouses whose relatives died with end-stage dementia in nursing homes in both Northern Ireland (NI) and the Republic of Ireland (Rol). A second aim is to develop guidelines for nursing home staff for the delivery of quality care in residents with end stage dementia in residential institutions.

Design/methodology/approach - This study had two phases. Phase one involved conducting in-depth qualitative interviews with spouse caregivers whose relatives had died from dementia in long stay care environments. Phase two entailed incorporating the information gathered through the in-depth interviews into draft guidelines and disseminating these to a multi-disciplinary group of health service professionals for their critical appraisal and ratification.

Findings - Findings showed that the EOL care delivered was deemed by most elderly spouses to be of high quality, with person centred, individual, kind, professional care highly valued. Areas of dissatisfaction noted included poor communication, lack of involvement in key decision making, and poor symptoms control.
\end{abstract}

Originality/value - Based on the study's findings, guidelines for the delivery of quality care in long stay residential institutions are developed in consultation with eight health service professionals. The authors hope these guidelines will contribute to improvements in the care of people with dementia at end of life and will form the basis for the future development of policy, practices and procedures.

Keywords Care, Dementia, End of life, Bereaved spouses, Quality of life, Nursing homes, Guidelines Paper type Research paper

\section{Introduction}

Whilst a myriad of quality standards exists for older people living in care homes and nursing homes in the UK, Ireland and Northern Ireland (NI), it has been argued that generic standards and guidelines are inadequate for older people dying with end stage dementia in nursing homes, whose unique and complex needs are often poorly understood, inappropriately addressed and regularly neglected. It is noted that too little or too much is often done for these people in environments which hinder rather than support optimal care (Downs et al., 2006). The needs of this large group of people with dementia (PwD) approaching end of life (EoL) are so particularly challenging that they clearly warrant independent dementia-specific guidelines.

The primary aim of this study was to contribute to improving quality of life for people with end stage dementia living in residential care settings by investigating the experiences of elderly spouses whose relatives had recently died with end-stage dementia in nursing homes in both $\mathrm{NI}$ and the Republic of Ireland (Rol). A second aim was to develop guidelines for nursing home staff for the delivery of quality care in end stage dementia in long stay residential institutions. 


\section{Background}

A literature review was carried out using the online search engine PubMed and the search terms, "dementia", "end of life", "palliative care", "residential care", and "Alzheimers". In addition articles were located through bibliographical searches from these papers as well as from the key UK and Irish reports. This review summarises the key findings from this search.

People dying from and with a dementia are an especially vulnerable group. Their EoL care needs may be further complicated by cognitive impairment; the prolonged illness trajectory, pain and communication difficulties, challenging behaviours and often the absence of staff specifically trained to manage both EoL and dementia care issues. It has been argued that good EoL care is dependent on sound clinical leadership, education for care staff and a more collaborative approach with families (Ryan et al., 2009). In this way a coherent, relationship-centred approach can be achieved (Ryan et al., 2009). Tilly and Fok (2008) recommend the importance of consistency in individualised or person-centred care approaches, the development of relationships between staff and residents and increasing staff knowledge of individual resident's needs, abilities and preferences. Volicer et al. (2001) advocate for appropriate management of symptoms (pain) and behaviours for those with advanced dementia, the involvement in programs such as hospice, and decisions regarding various medical interventions. A crucial component of EoL care, he and his colleagues argue, is the transmission of information to the resident's surrogate decision maker. The benefits and burdens of interventions and the development of a care plan that considers previous wishes of the resident, if any are vital to ensure the resident's best interests as interpreted by the decision maker.

Several experts (Bayer, 2006; Tilly and Fok, 2008) writing about death and dementia have called for care to extend beyond symptom control to encompass the patient's psychological and spiritual needs as well as a consideration of the needs of their families who have often borne the burden of care for many years.

In a powerful BMJ editorial, Hughes et al. (2005) make a case for specialist hospices for people with advanced dementia and call for the use of palliative care approaches which foster holistic care. They argue that by encouraging an empathic approach, reflected in a social environment rich with meaningful activities, the judicious use of medicine and specialist teams, quality of life for PwD can be nurtured and enhanced.

One of the largest prospective studies, which looked at 438 people who developed dementia in England and Wales has highlighted that PwD need a wide range of coordinated care and support from a variety of services (Xie et al., 2008). In another article (Robinson et al., 2005), a call for the development of practice guidelines for EoL care and dementia was made and an argument marshaled that compared with cancer care, there was little practical guidance on the provision of EoL care in dementia. The recently completed National Audit of EoL Care in Hospitals undertaken, by the Hospice Friendly Hospitals (McKeown et al., 2010), assessed quality of care provided by Irish hospitals in the last week of life. It concluded that quality of care and quality of life for those dying in Irish hospitals was good. It was noted in this study that experiences are influenced by patients' symptoms and the type of care provided and that the latter in turn determine relatives' views of death.

\section{Methodology}

This study had two phases. Phase 1 involved conducting in-depth qualitative interviews according to a piloted protocol with 16 elderly spouse caregivers (eight from $\mathrm{Nl}$ and eight from Rol) whose relatives had died from dementia in long stay care environments. The purpose of these interviews was to collect information on family caregivers' experiences of their spouses' EoL care. Phase 2 entailed incorporating the information gathered through the in-depth interviews into draft guidelines and disseminating these to a multi-disciplinary group of health service professionals for their critical appraisal and ratification. The draft guidelines were accordingly amended. 
Sampling. The sample of bereaved spouses was recruited through statutory and independent nursing homes, carers' organisations, Nursing Homes Ireland and the Independent Health and Care Providers in NI. Inclusion criteria were:

- Death of a spouse due to dementia within the last six months to two years[1].

- Availability and agreement of bereaved spouse to participate in an in-depth interview.

Ethical approval in Rol was obtained through Trinity College Dublin. The process was far more complicated and prescriptive in $\mathrm{NI}$ as ORECNI required that Nursing Homes needed to make direct contact with potential subjects and contact details for potential participants could only be accessed by the research team after completed consent forms were returned.

A total of 192 nursing homes were contacted (170 in NI and 22 in Rol). Eight bereaved spouses were recruited in the Rol, three through Caring for Carers, two from a dementia unit in a private nursing home, two from a Health Service Executive nursing home and one from a general private nursing home. In $\mathrm{NI}$ an additional eight bereaved spouses were obtained from five independent nursing homes and one supported housing scheme. The final sample consisted of 18 bereaved spouses.

Data collection instrument. Drawing extensively on Volicer et al.'s (2001) original work where three scales and sub-scales were devised, an interview schedule was designed to examine older spouses' experiences of the time period leading up to and surrounding their relatives' death. The interview schedule was divided into seven sections:

1. Sections 1 and 2, collected socio-demographic data and explored the profiles of the deceased and the bereaved spouses.

2. Section 3 collected general information about the time spent by the deceased in the nursing home.

3. Section 4 explored quality of care issues in the last 90 days prior to death.

4. Section 5 explored symptom and pain control.

5. Section 6 investigated comfort control approaching death.

6. Section 7 the final part of the interview schedule (not reported on here) examined post-bereavement experiences.

The instrument was piloted on two bereaved spouses and subsequently revised and confirmed.

Data analysis. A qualitative thematic analysis (Seale et al., 2007) was used. Interviews were recorded and transcribed. One researcher initially read and re-read the transcripts to ensure familiarity with the interviews (Denscombe, 2007) and to ensure no subtleties had been missed. Responses pertaining to individual questions from each interviewee were summarised on a structured table and key quotes noted. This information was then scrutinised and themes emerging from the data identified. The research team discussed the initial findings and then verified the interpretations through examination of the transcribed interviews. Minor adjustments were made and findings discussed and agreed.

\section{Phase 2}

Based on Phase 1 findings, guidelines to assist nursing homes to develop policies and practices on EoL care for residents with dementia were developed.

Sampling. These guidelines were then circulated to a selected sample of eight professionals who were invited to read the guidelines and provide feedback. Professionals included a geriatrician, old age psychiatrist, two palliative care physicians, three specialist nurses, and a dementia expert. These professionals were well known to each of the three researchers. 
Table I reports findings on the socio-demographic profile of the sample of bereaved family caregivers. All but four of the sample were elderly widows whose mean age was 77 (range was 62-88 years). Most had been in long-term marriages, with the mean duration of marriage 46 years (range was 18-60 years).

Table II reports findings on key characteristics of the sample of deceased men and women. It shows that the majority of the deceased were men whose mean age at death was 81 years. Most (13 out of 16) had a formal diagnosis of dementia but only one had been told of his diagnosis. Diagnoses tended to be made by either psychiatrists or GPs and other health service professionals. The mean length of stay in nursing homes was almost three years (33 months). In all but two of the death certificates, dementia was not mentioned as the primary cause of death. In seven cases dementia was referred to as being a secondary cause of death. All but three of these deaths occurred in nursing homes. The remaining deaths occurred in hospitals.

\section{Satisfaction with care}

Quality of care at EoL (last 90 days). In response to a series of questions asked about how the Nursing Home cared for the deceased person during the last 90 days of life, 13 out of 16 respondents reported that their relative received good care. The same 13 respondents stated that their relative was kept comfortable during the last 90 days of life. All but two respondents claimed their spouses received the nursing care needed and 12 out of the 16 respondents interviewed (75 percent) described the care received from nursing home staff in very positive terms.

When asked to identify what staff actions were taken to ensure their relative's comfort during this period, good personal care emerged as the greatest contributor to resident comfort. Caregivers' narratives revealed how this support was provided practically and honed in on issues such as personal hygiene, body temperature, and maintaining the dignity of their dying spouse.

Just changing him regularly, keeping him dry and they turned him in and out, they made sure he wasn't lying on one side and he got turned over. I wouldn't say there was any one thing it was just the general care, it was just good all round care [...] He never had any skin breakdown, he was well nourished, they took time to feed him if I wasn't there. He always looked nice, his clothes were clean (NI6)

I think all those little things, that he was made really comfortable physically. They were very understanding just down to how warm he was, how cold he was you know, what he needed on top of him, his pillows you know just very small details like giving his face and hands a wee wipe because they felt a bit clammy or you know changing quilts, changing sheets. It was excellent care (NI2).

\section{Person-centred care}

The perceived caring attitudes of nursing home staff, their professionalism, and the person/relationship-centred way in which EoL care was delivered to dying spouses emerged as the most valued aspects of care for 14 out of the 16 respondents (88 percent). Most

\begin{tabular}{lcc}
\hline Table I The socio-demographic characteristics of bereaved spouses & $n=16$ & $\%$ \\
\hline$n$ & & 75 \\
\hline Gender of bereaved spouse & 12 & 25 \\
Female & 4 & 77 \\
Male & $62-88$ & \\
Mean age of bereaved spouse & 46 years & $18-60$ \\
Range & 34 months \\
Mean number of years married & $8-100$ \\
Range &
\end{tabular}




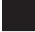

$n=16$

Gender of deceased spouse

Female

Male

Mean age of bereaved spouse

Range

Formal prior diagnosis of dementia

Yes

Probably

No formal diagnosis of dementia

Diagnosis made by

Psychiatrist

GP and or others

Psycho-geriatrician

Neurologist

Consultant and other

Person with dementia told diagnosis

Yes

No

Not sure

Mean length of time in nursing home

4

Dementia as primary cause of death Yes

Dementia named as other significant cause of death

bereaved spouses also commented on the way in which nursing home staff monitored and spent time physically in the company of their relatives when they themselves were unable to be present. Knowing that staff were physically present with their dying relatives inspired trust and relieved anxiety. Many were also pleased that staff continued to verbally communicate with their dying relatives, even in circumstances when the latter could no longer understand verbal communication. Bereaved spouses reported they appreciated their dying relative being treated with dignity and empathy, being listened to, being treated as normal people and on occasion, being joked with:

You know they were talking to him, they were laughing with him, they were joking. I don't know how much he understood and they would have come in you know when they wouldn't have had to come in. They were sort of with him constantly you know so it was sort of very very good (NI2).

If you came and slipped quietly down to his room before you went in you could hear somebody talking to him and calling his name and that kind of thing so it wasn't a pretence to us, it was what happened (Rol4)

What I loved most was that they would get down if he was sitting in his reclining chair. They got down on their hunkers so that they were at eye level with him to try to figure out what he was trying to get across (NI6)

\section{Pain and symptom control at EoL}

12 (75 percent) of the sample acknowledged that their spouse did not appear to be in pain 
Findings also showed that bereaved spouses had a high level of confidence in the medical care administered during the last 90 days of life. Confidence levels in the medical care was marginally higher in $\mathrm{NI}$ (87 percent) compared with Rol (75 percent). Medical care at EoL was interpreted by most as care provided by GPs. Lack of confidence $(n=3)$ was related to the absence of regular GP visits to the nursing home and the need for GP training in dementia. None of the 16 respondents claimed their relative was under-treated at EoL and only one person stated that her spouse was over-treated. In this case the gentleman, according to his wife, was admitted too often and unnecessarily to hospital:

It was too often and not doing him any good (NI7).

According to bereaved spouses, the most important aspect of medical care was the individualised attention given by GPs. Only one respondent experienced a community palliative care team approach, where the GP, nurses and palliative care specialists worked collaboratively in delivering care. In two other cases the dying person experienced EoL care in a facility where nurses were specially trained in palliative care. In general these spouses' experiences of palliative care teams $(n=1)$ and palliative care approaches $(n=2)$ were very positive:

The palliative care team came in a lot. Matron suggested they call in palliative care. When the lady from palliative care came in we had music on in the corner of the room but it was like running water. We were all sitting around and she just said, "this is lovely and peaceful and xxx is so lucky". It was lovely having her there [...] (Rol4).

\section{Hospital care}

Six spouses reported very unpleasant experiences relating to the impact of hospitalisation on the wellbeing of the person with dementia. They referred to hospital environments being inappropriate and that staff lacked the knowledge and skills necessary to care for PwD:

I don't think general hospitals provide for people with dementia [...] they just don't have the facilities (NI2).

They weren't able to cope with the dementia side of things and they'd have been ringing me up at all hours of the night to say $X$ wants to speak to me you know and sometimes she would be pacified but when I would go in she was usually in a terrible state wandering about. That was a very difficult time (NI3).

He used to be terribly disturbed by going into hospital (Rol2).

\section{Staff training}

Whilst no specific questions were asked about staff training on specialist EoL and dementia care, six respondents volunteered information on this topic. Three people referred specifically to the importance of and need for general dementia staff training:

Every nursing home should have people who understand dementia (NI3).

There has to be a lot more training and a lot more in-depth training - not just about the symptoms of dementia (NI2).

Three other respondents made particular reference to the need for specialist training in 337 palliative care and specialist dementia care:

I think staff both medical and nursing should have more training in treating dementia patients [. . . ] I think medical care should be provided by a specialist in dementia and not a GP - who, as far as I know, only sees a patient when called in due to illness [...] there were no specialist nurses or others to provide palliative care (Rol6). 
Half the sample $(n=8)$ reported they had major decisions to make during the last three months of care and six of these men and women felt fully informed about and involved in the decision-making process. Important decisions centred around:

- Admissions to hospital 4 (25 percent).

- Removal of PEG feeding 1 (6 percent).

- Treatment decisions including treatment for other illnesses 2 (13 percent).

- Medication withdrawal 1 (6 percent).

Being kept informed and working in partnership with staff was deemed important particularly when decisions had to be taken in the best interests of the person with dementia. A few interviewees emphasised the importance of taking time, if available, to ensure the right decision was being taken.

I took my time and figured out whether it was the right thing or what was the best thing to do rather than just running into it without thinking about it and afterward then realising it was a mistake (NI8)

The person who is not affected is left with all the decisions. These decisions were so tough [...] the three GPs in the practice and they had spent a lot of time with me and explained that this is what's going to happen if we keep this in you know so I was well enough informed about that (NI2).

Only two respondents reported not being well prepared for decision-making at their relatives' EoL. Both these spouses had been advised about the need for hospitalisation (in one case by the GP, and in the other by nursing home staff) and asked if they wished their relative's hospital admissions to proceed. Their responses reflected that they were unprepared to make such decisions and had difficulty understanding the responsibility involved. These bereaved spouses claimed they ultimately based their decisions on the best interests of the person with dementia. Although only one dying person had made an Advanced Directive, other bereaved spouses involved in decision-making claimed that knowing what they considered to be appropriate and "right" for their relative made decision-making easier.

\section{Relationships}

Bereaved spouses frequently referred to their evolving relationships with nursing home staff and with other residents and their family members. Relationships were fostered and developed through regular and often daily visiting, to the extent that several bereaved spouses expressed feelings of being part of a family within the nursing home. The comment of one bereaved spouse echoed the views of several others. She reported:

Well I felt like part of a family. And somehow or other they treated him like a member of the family you know [...]. I think the dementia unit is like a family you know all the residents are like part of one big family [...]. I think they were feeling what I was feeling to a degree, what my family were feeling, because he was like part of their family (NI2).

Over time, regular visits and liaison with staff engendered trust:

Complete and total trust in the decisions that were made here. I had total confidence in the decisions here (Rol4).

Extremely understanding they just [...] they knew exactly how to deal with things as they arose (NI4).

I knew that he was getting the best possible care. I wouldn't have been happy if he was being neglected (NI1).

Not everyone could visit on a daily or frequent basis, because of transport, health or debility and the three people who were generally dissatisfied with care were the same three spouses 
No interviewee referred to anything in the nursing home that was deemed unsupportive at the time of death. In response to another question asked about grief, nobody stated that their grief had been affected negatively by the actions of the nursing home staff.

The support and understanding of staff was especially valued by bereaved spouses at the time of death. All those who experienced good care thought staff were very understanding of the needs of the person with dementia at EoL and also mentioned to how they trusted the nursing home staff. Interestingly two of the three people who had concerns about care in general claimed they were content about the care provided during the last week of the life of the person with dementia.

\section{Phase 2 results}

Based on findings from these interviews, draft guidelines to assist individual nursing homes to develop policies and practices in relation to EoL care for residents with dementia was developed and circulated to the multi-disciplinary group for their critical appraisal. These guidelines centred around five core areas:

1. Person-centered care underpinned by a knowledge of the dying person's life history.

2. Good personal-care based on ongoing assessment and attention to detail.

3. Staff-training in the needs of PwD at the EoL.

4. A partnership approach with the nursing home fully integrated into local health care systems.

5. A shared approach to care with trusting relationships between the spouse and the nursing home and the spouse's involvement in and support with decision-making.

The guidelines were subsequently reviewed and revised in accordance with the helpful feedback received from the eight health service professionals. A revised guideline was then completed.

\section{Conclusions}

Our findings show that the bereaved spouses who participated in this study were mainly satisfied with the level of care their relatives with dementia received at EoL as residents of nursing homes. About 14 out of 16 interviewed reported their spouses received all the care required in the last three months of life and 12 out of 16 described care in very positive terms using words such as "excellent", "superb" and "second to none". Some might reflect that elderly spouses would have a vested interest in believing that the care that their partner received was exemplary as to not think so could be a source of self-guilt and recrimination. However, the praise for staff and for the kindness and professionalism experienced was so clear and resounding it would be hard to think it was anything other than truly authentic. None of those interviewed believed their relative was under-treated at his or her EoL and only one respondent claimed that the deceased person was over-treated. Three quarters reported their relative was in no pain during the last 90 days of living.

Good personal, care underpinned by a person-centred philosophy that was inclusive of family members, and that enabled them to participate in appropriate decision making at EoL, was reported as most valued. Bereaved spouses who were satisfied with the care offered, appreciated working in partnership with health service professionals and were kept well informed about issues of relevance to their relatives' care and comfort.

Overall our findings support the literature and suggest that from the caregivers' perspective, good EoL care was dependent on clinical leadership, collaborative approaches, staff education (Ryan et al., 2009) and individualised person-centred care (Tilly and Fok, 2008) which spawned trust in relationships between staff, relatives and residents. Whilst the case for specialist hospice care for those dying with dementia did not emerge in this research, nonetheless it is worth noting that the three families who had the opportunity to experience 
palliative care approaches were very appreciative of the same. The need for EoL care to extend beyond symptom control and explicitly encompass the patient's psychological and spiritual needs, as well as the needs of family caregivers (Bayer, 2006), did not emerge as salient in this study. It is worth noting that in relation to the three respondents who were critical of the nursing home care provided, none were in a position to visit the nursing home on a daily basis.

This study shows that the care delivered to residents living in nursing homes with dementia at the EoL was deemed by the spouses interviewed to be of high quality. In particular, person centred, individual, kind and professional care is valued, as is the capacity for nursing home care staff to develop close working relationships with both residents and their families. Poor communication, lack of involvement in key decisions, and any sense of the resident not being treated respectfully as a person, or not well symptom controlled, were particular areas of dissatisfaction for a few of these spouses. The subsequent guidelines produced were well received by health care professionals with the reservation that in order to be effective such guidelines need to be practical, and many of these areas relate to an underlying philosophy of good quality care. Finally, we hope that the information gained from the research interviews and the resultant guidelines developed will contribute to improvements in the care of PwD at EoL and should form a basis for the future development of policy, practices and procedures.

Implications for policy and practice
- PwD approaching the end of their lives in nursing homes are particularly vulnerable. They require
individualised care that promotes quality of life and is totally respectful of the dying person's
holistic needs.
- All EoL care should promote dignity through excellent personal care.
- All staff involved in the delivery of EoL care to residents with end stage dementia should receive
regular training and guidance in caring for PwD, so that they maintain their skills to deliver quality
care.
- The nursing home should be proactive in seeking integration within their local health care system
through developing relationships with all professionals involved in the delivery of care to residents
with dementia.
- EoL care must reflect an understanding of, and support for family members' needs and foster a
sense of partnership and trust between staff, residents and their families.

\section{Note}

1. Due to difficulties accessing the sample the time since death criterion had to be revised considerably.

\section{References}

Bayer, A. (2006), "Death with dementia: the need for better care", Age and Ageing, Vol. 35 No. 2, pp. 101-2, available at: html">http://ageing.oxfordjournals.org/content/35/2/101.full.pdf + html (accessed 23 August 2010).

Denscombe, M. (2007), The Good Research Guide for Small Scale Social Research Projects, Open University Press, Buckingham.

Downs, M., Small, N. and Froggatt, K. (2006), "Explanatory models of dementia: links to end-of-life care", International Journal of Palliative Nursing, Vol. 12 No. 5, pp. 209-13.

Hughes, J.C., Robinson, L. and Volicer, L. (2005), "Specialist palliative care in dementia", British Medical Journal, Vol. 330 No. 7482, pp. 57-8.

McKeown, K., Haase, T. and Twomey, S. (2010), "Dying in hospital in Ireland: family perspectives", Report 3, Irish Hospice Foundation, Dublin, available at: www.hospicefriendlyhospitals.net/images/ stories/pdfs/Report-3-Dying-in-Hospital-in-Ireland-Family-Perspectives.pdf(accessed 27 August 2010). 
Robinson, L., Hughes, J., Daley, S., Keady, J., Ballard, C. and Volicer, L. (2005), "End-of-life care and dementia", Reviews in Clinical Gerontology, Vol. 15 No. 2, pp. 135-48.

Ryan, T., Ingleton, C., Gardiner, C., Nolan, M. and Gott, M. (2009), "Supporting people with dementia to die with dignity", Nursing Older People, Vol. 21 No. 5, pp. 18-23.

Seale, C., Gobo, G., Gubrium, J. and Silverman, D. (2007), Qualitative Research Practice, Sage, London.

Tilly, J. and Fok, A. (2008), "Policy barriers to quality end-of-life care for residents with dementia in assisted living residences and nursing homes", Alzheimer's Care Today, Vol. 9 No. 2, pp. 103-12.

Volicer, L., Hurley, A.C. and Blasi, Z.V. (2001), "Scales for evaluation of end-of-life care in dementia", Alzheimer Disease and Associated Disorders, Vol. 15 No. 4, pp. 194-200.

Xie, J., Brayne, C. and Matthews, F.E. (2008), "Survival times in people with dementia: analysis from population based cohort study with 14 year follow-up", British Medical Journal, Vol. 336 No. 7638 , pp. 258-62.

Further reading

Alzheimer's Research Trust (2010), "Demographics", available at: www.alzheimersresearchuk.org/ dementia-statistics/ (accessed 23 August 2010).

Department of Health (2003), Care Homes for Older People: National Minimum Standards, Department of Health, London, available at: www.dh.gov.uk/prod_consum_dh/groups/dh_digitalassets/@dh/@en/ documents/digitalasset/dh_4135403.pdf (accessed 25 August 2010).

Department of Health (2008), End of Life Care Strategy: Promoting High Quality Care for All Adults at the End of Life, Department of Health, London, available at: www.dh.gov.uk/prod_consum_dh/groups/dh_ digitalassets/@dh/@en/documents/digitalasset/dh_086345.pdf (accessed 25 August 2010).

Department of Health (2009), End of Life Care Strategy: Quality Markers and Measures for End of Life Care, Department of Health, London, available at: www.dh.gov.uk/prod_consum_dh/groups/dh_ digitalassets/documents/digitalasset/dh_101684.pdf (accessed 25 August 2010).

Department of Health, Social Security and Public Safety Northern Ireland (2008), Residential Care Homes Minimum Standards, Department of Health, Social Security and Public Safety Northern Ireland, Belfast, available at: www.dhsspsni.gov.uk/care_standards___residential_care_homes.pdf (accessed 25 August 2010).

Department of Health, Social Services and Public Safety Northern Ireland (2008), Nursing Homes Minimum Standards, Department of Health, Social Services and Public Safety Northern Ireland, Belfast, available at: www.dhsspsni.gov.uk/care_standards___nursing_homes.pdf (accessed 25 August 2010).

Department of Health, Social Services and Public Safety Northern Ireland (2009a), Northern Ireland Health and Social Care Services Strategy for Bereavement Care, Department of Health, Social Services and Public Safety Northern Ireland, Belfast, available at: www.dhsspsni.gov.uk/nihsc-strategy-forbereavement-care-june-2009.pdf (accessed 25 August 2010).

Department of Health, Social Services and Public Safety Northern Ireland (2009b), Palliative and End of Life Care Strategy for Northern Ireland Consultation Document, Department of Health, Social Services and Public Safety Northern Ireland, Belfast, available at: www.dhsspsni.gov.uk/palliative_and_end_of_ life_care_strategy_-_consult.pdf (accessed 25 August 2010).

Department of Health, Social Services and Public Safety Northern Ireland (2010), Improving Dementia Services in Northern Ireland: A Regional Strategy Consultation Paper, Department of Health and Social Services and Public Safety Northern Ireland, Belfast, available at: www.dhsspsni.gov.uk/improvingdementia-services-in-northern-ireland-consultation-may-2010.pdf (accessed 25 August 2010).

Health Information and Quality Authority (2008), National Quality Standards for Residential Care Settings for Older People in Ireland, Health Information and Quality Authority, Cork, available at: www.hiqa.ie/ system/files/HIQA_Residential_Care_Standards_2008.pdf (accessed 27 August 2010).

Hospice Friendly Hospitals (2010), Quality Standards for End-of-life Care in Hospitals Making End-of-life Care Central to Hospital Care, Irish Hospice Foundation, Dublin, available at: www. hospicefriendlyhospitals.net/images/stories/pdfs/Quality_Standards_for_End_of_Life_Care_in_ Hospitals.pdf (accessed 27 August 2010). 
Irish Hospice Foundation (2002), Standards for Bereavement Care, Irish Hospice Foundation, Dublin.

Irish Hospice Foundation and the Health Service Executive (2008), Palliative Care for All Integrating

Palliative Care into Disease Management Frameworks, Irish Hospice Foundation and the Health Service

Executive, Dublin, available at: www.hse.ie/eng/services/Publications/services/Older/Palliative_care_ for_all1.pdf (accessed 27 August 2010).

National Care Forum (2007), Key Principles of Person-centred Dementia Care Statement of Best Practice, National Care Forum, Coventry, available at: www.nationalcareforum.org.uk/content/Key\% 20principles\%20of\%20person-centred\%20dementia\%20care.pdf (accessed 27 August 2010).

Volicer, L. (2008), "End-of-life care for people with dementia in long-term care settings", Alzheimer's

Care Today, Vol. 9 No. 2, pp. 84-102.

Corresponding author

Suzanne Cahill can be contacted at: cahillsu@tcd.ie 
Author Queries $\quad 628$

JOB NUMBER: 145455

JOURNAL: QAOA

Dear Author 633

Please address all the numbered queries on this page which are clearly identified 634 on the proof for your convenience.

Thank you for your cooperation

No Quries 